\title{
GENERALIZATIONS AND SHARPENINGS OF CERTAIN BERNSTEIN AND TURÁN TYPES OF INEQUALITIES FOR THE POLAR DERIVATIVE OF A POLYNOMIAL
}

\section{THANGJAM BIRKRAMJIT SINGH* AND BARCHAND CHANAM}

Abstract. Let $p(z)$ be a polynomial of degree $n$. The polar derivative of $p(z)$ with respect to a complex number $\alpha$ is defined by

$$
D_{\alpha} p(z)=n p(z)+(\alpha-z) p^{\prime}(z) .
$$

If $p(z)$ has all its zeros in $|z| \leqslant k, k \geqslant 1$, then for $|\alpha| \geqslant k$, Aziz and Rather [Math. Inequal. Appl., 1, (1998), 231-238] proved

$$
\max _{|z|=1}\left|D_{\alpha} p(z)\right| \geqslant n\left(\frac{|\alpha|-k}{1+k^{n}}\right) \max _{|z|=1}|p(z)| .
$$

In this paper, we first improve as well as generalize the above inequality. Besides, we are able to prove an improvement of a result due to Govil and Mctume [Acta Math. Hungar., 104, (2004), 115-126] and also prove an inequality for a subclass of polynomials having all its zeros in $|z| \geqslant k, k \leqslant 1$.

Mathematics subject classification (2020): 30A10, 30C10, 30D15.

Keywords and phrases: Polynomial, polar derivative, inequality.

\section{REFERENCES}

[1] A. AzIZ, Inequalities for the derivative of a polynomial, Proc. Amer. Math. Soc., 89, (1983), $259-266$.

[2] A. AzIZ AND Q. M. DAwood, Inequalities for a polynomial and its derivative, J. Approx. Theory, 54, (1988), 306-313.

[3] A. AzIZ AND N. A. RATHER, A refinement of a theorem of Paul Turán concerning polynomials, Math. Inequal. Appl., 1, (1998), 231-238.

[4] A. AzIZ And W. M. SнAн, Inequalities for a polynomial and its derivative, Math. Inequal. Appl., 7, 3 (2004), 379-391.

[5] A. AZIZ AND B. A. ZARGAR, Inequalities for the maximum modulus of the derivative of a polynomial, J. Inequal. Pure and Applied Math., 8, (2007), 1-8.

[6] S. BERNSTEIN, Lecons sur les proprietes extremales, Collection Borel, (1926).

[7] V. N. Dubinin, Distortion theorems for polynomials on the circle, Mat. Sb., 191, (2000), 1797-1807.

[8] N. K. Govil, On the derivative of a polynomial, Proc. Amer. Math. Soc., 41, (1973), 543-546.

[9] N. K. Govil, On a theorem of S. Bernstein, Proc. Natl. Acad. Sci., 50, (1980), 50-52.

[10] N. K. Govil, Some inequalities for derivatives of polynomials, J. Approx. Theory, 66, (1991), $29-35$.

[11] N. K. Govil And P. Kumar, On sharpening of an inequality of Turán, Appl. Anal. Discrete Math., 13, (2019), 711-720.

[12] N. K. Govil And G. N. Mctume, Some generalizations involving the polar derivative for an inequality of Paul Turán, Acta Math. Hungar., 104, (2004), 115-126.

[13] N. K. Govil AND Q. I. Rahman, Functions of exponential type not vanishing in a half-plane and related polynomials, Trans. Amer. Math. Soc., 137, (1969), 501-517.

[14] P. Kumar, On the inequalities concerning polynomials, Complex Anal. Oper. Theory, 14:65, (2020). 
[15] P. Kumar and R. Dhankhar, Some refinements of inequalities for polynomials, Bull. Math. Soc. Sci. Math. Roumanie, 63, 111 (2020), 359-367.

[16] A. Mir, A. WANI AND M. H. Gulzar, Some inequalities concerning the polar derivative of a polynomial, J. Interdiscip. Math., 21, 6 (2018), 1387-1393.

[17] N. A. RATHER, I. DAR AND A. IQBAL, On a refinement of Turán's inequality, Complex Anal. Its Synerg., 6:21, (2020).

[18] P. D. LAX, Proof of conjecture of P. Erdös on the derivative of polynomial, Bull. Amer. Math. Soc., 50, (1944), 509-513.

[19] P. TURÁN, Uber die Ableitung von Polynomen, Compos. Math., 7, (1939), 89-95. 